\title{
Hydropower Potential from the AUSINO Drinking Water System ${ }^{+}$
}

\author{
Giacomo Viccione ${ }^{1, *}$, Rosaria Amato ${ }^{1}$ and Massimo Martucciello ${ }^{2}$ \\ 1 Department of Civil Engineering, University of Salerno, 84084 Fisciano, Italy; rosaria.amato01@gmail.com \\ 2 Ausino S.p.A., Servizi Idrici Integrati, 84013 Cava De' Tirreni, Italy; massimomartucciello@ausino.it \\ * Correspondence: gviccion@unisa.it; Tel.: +39-089-96-3408 \\ + Presented at the 3rd EWaS International Conference on "Insights on the Water-Energy-Food Nexus", \\ Lefkada Island, Greece, 27-30 June 2018.
}

Published: 1 August 2018

\begin{abstract}
The urban water cycle spends energy to provide communities drinking water and to treat produced wastewater. The same cycle can also provide energy by exploiting the kinetic energy of water flowing into the network to turn turbines and generate electricity. In this framework, this work focuses on the hydropower potential arising from the installation of a water turbine at the end of the pipeline of the water supply system "New Aqueduct", managed by the "Ausino S.p.A. Servizi Idrici Integrati" in the Campania Region, Italy. The plant allows to reach-in some circumstances-a minimum power level at which the return of the investment occurs in a reasonable time period. In facts, the supply system exhibits somewhere pressure heads of up to hundreds meters, a matter which has been seen of a certain relevance as attenuation systems such as pressure relief valves were adopted to reduce pressure levels. Today, this related 'waste of available potential energy' can be conveniently avoided by installing proper energy recovery apparatuses as detailed in this study.
\end{abstract}

Keywords: hydropower; renewably energy source; RES; drinking water supply; turbines

\section{Introduction}

Among renewable energy sources (RES), hydropower is rather widespread over the Italian country due to its peculiar features. Till sixties, hydropower in Italy contributed to cover up to $87 \%$ of the supply needs. Then the nationalization of the power generation, the non-stop increasing of the energy consumption as a consequence of the economic upturn and the strategic review on energy production caused a downfall of the abovementioned percentage because of the widespread exploitation of conventional thermoelectrical power stations based on fossil fuels, e.g., oil, coil or gas. Presently, hydroelectric power accounts only for $1 / 6$ of the country's electricity output.

Most of the available ordinary sources, i.e., lakes, storage basins etc., are currently exploited by large hydropower plants. Therefore, building new ones, at least those of bigger size seems not to be a practical option. Nevertheless, increasing hydropower production is still feasible by improving the efficiency of existing plants or with the fulfilment of new small (SHPs) or micro-hydropower (MHPs) plants [1-3] which exploit available high pressures, commonly dissipated by controlling valves (e.g., pressure relief valves) instead. In facts, in recent years a new concept of hydropower plants is taking hold due to the related low impact on the ecosystems and the availability of diffused contained energy water resources. Existing tunnels, channels, pipelines, aqueducts conveying raw water can be fitted with electric power generation. It is worth mentioning at this regard some high value payback investments: starting from 2008 high-pressure flows in the pipelines managed by the San Diego Water County Authority allows to generate electricity through a 4.5 MW turbine generator, reducing the need of importing power. Recently, the EYDAP authority realized six small 
hydropower plants along the managed aqueducts serving the city of Athens, for a total production of 4.6 MW. By the mid of 2017, the Water Supplies Department of Hong Kong will construct $500 \mathrm{~kW}$ hydropower facilities at a water treatment works. In Italy, hydropower plants are widespreading especially in the North e.g., in Lombardia, Trentino Alto Adige and Piemonte Regions [4]. Other case studies of interest are reported in [5-7].

A number of advantages arise from the operation of small hydropower plants: exploitation of available, yet unused hydraulic energy potential, exploitation of existing infrastructures, production of environmentally friendly energy, protection of the environment, since energy production from RES does not involve the dispersion of pollutants $\left(\mathrm{CO}_{2}\right.$ as well as other toxic volatile components are cut down), tax income from the sale of electricity, Green Certificates and all-inclusive feed-in tariff mechanisms, new job opportunities, low maintenance and operational costs, possible achievement of the carbon free electricity generation target by 2050. The Italian legislation incentivize the energy production from RES promoting feed-in tariff mechanisms. In facts, the 2009/28/EC Directive on quality of drinking water has been transposed in Italy with the Ministerial Decree 23/06/2016 "Incentivazione dell'energia elettrica prodotta da fonti rinnovabili diverse dal fotovoltaico. (16A04832)". Possible disadvantages, yielding undesired effects are: the possible inception of cavitation in turbines causing vibration, blade surface damage and performance loss [8], the load rejection during operation because of high fluctuations in the grid parameters [9], effects related to the climate change $[10,11]$.

The case of study, next presented, concern a portion of the aqueduct located in the area of Cava $\mathrm{de}^{\prime}$ Tirreni municipality, Campania region, Italy, where available flow rates and pressure heads allow the fulfilment of a small hydropower plant of significant size. The related investigation was carried in collaboration with the AUSINO S.p.a. Servizi Idrici Integrati, a joint stock company, publicly owned, entitled of the integrated water service of the Amalfi coast, Salerno main city and other nearby municipalities.

\section{Materials and Methods}

\subsection{The New Aqueduct}

The pipeline under investigation is sketched in Figure 1. The "New aqueduct" starts from the "Nuova Olevano" spring, in the municipality of Acerno. A steel pipe DN 800 connects the spring to several tanks, serving different villages. In correspondence to the "Varco della Foce" gallery the line splits in two branches, by means of a free surface divider, respectively serving the Croce tank and the Pietrasanta tank with a steel pipe DN 250, the latter nearby the municipality of Cava de Tirreni.

\subsection{The Flow Solver}

The aqueduct described in the previous section was implemented in the freely available software EPANET [12,13]. EPANET, developed by the United States Environmental Protection Agency (EPA), is a water distribution system modelling software package intended for the simulation of hydraulic and water-quality behaviour within pressurized pipe networks. Spatially and temporally varying water demand, pumps described by their internal curves, minor head losses arising from bends and various types of valves e.g. pressure and flow control, shutoffs and so on can be easily implemented. Depending on the specific element, mandatory input data must be provided (see Table 1).

Table 1. Input data to be provided for some network's elements.

\begin{tabular}{cc}
\hline Element & Input Data \\
\hline Junction & geometric height, inflow/outflow rate. \\
Pipe & length, diameter, roughness coefficient \\
Reservoir & geometric height, min and max flow level, inflow rate. \\
\hline
\end{tabular}




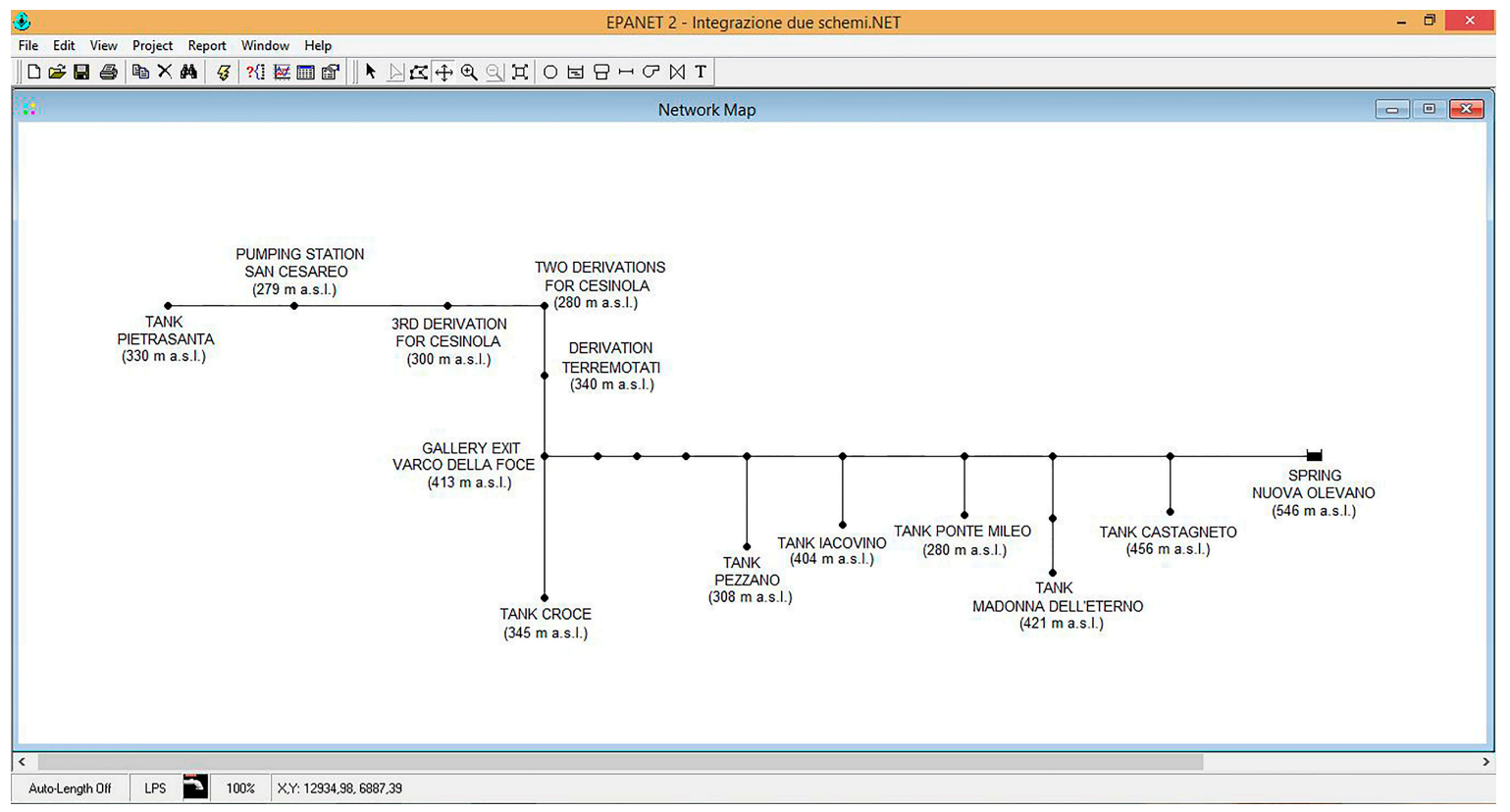

Figure 1. The "New Aqueduct" implemented in the EPANET environment.

The model provides the computed results in both graphical and tabular fashion, concerning e.g., mean velocity and volume flow rates in pipes, water levels at the tanks or pressure heads at the nodes. See Table 2 for an overview.

Table 2. Output results for some network's elements.

\begin{tabular}{cc}
\hline Element & Output Data \\
\hline Junction & Total head, pressure head, water quality \\
Pipe & Mean velocity, flow rate, piezometric, speed of reaction, water quality. \\
Reservoir & Net inflow, water level, quality \\
\hline
\end{tabular}

\subsection{Water Turbines}

Water turbines are mechanical devices used to transform the hydraulic energy of flowing water into mechanical rotational energy which is in turn converted into electricity when the turbine runner is connected to a generator. To develop a given power at a specified design head for the lowest possible cost of investment, the turbine and generator unit should have the highest speed attainable. However, the speed may be limited by undesired effects, such as cavitation, vibration, loss in efficiency. The efficiency of the turbine is given by the combination of both local hydraulic and losses in conjunction with the fact that only not all the inflow actively participates in the process of impinging the blades. In addition, the efficiency of the generator plays a certain role as well, in the production of electricity, due to losses at the transformer, the copper windings, magnetizing side effects in the core and the friction during the rotation.

In any case, turbines to be installed on aqueducts conveying drinking water have to satisfy specific characteristics in order not to alter liquid properties. In Italy, the components must comply with the Ministerial Decree 174/2004 "Regulation on materials and devices that can be used in fixed installations for capture, treatment, introduction and distribution of water intended for human consumption" which transposes the European Directive 98/83/EC on quality of drinking water.

In the present investigation, the Italian company IREM (www.irem.it) was contacted to assess which type of turbine can be installed on the basis of input data specified in the next section. 


\section{Results}

\subsection{Obtainable Power from the Actual Configuration}

On the basis of the monthly flow rates provided by the Ausino company from January 2017 to March 2018 (see Figure 2), an inflow at the Pietrasanta reservoir ranging from 50 1/s to 100 1/s was chosen for the next calculations. In particular, the minimum value was fixed as to be $10 \%$ lower than the corresponding minimum of the series for safety reasons. In the case of $\mathrm{Q}_{\mathrm{p}}=100 \mathrm{l} / \mathrm{s}$, the EPANET model correspondingly gives a pressure head $\mathrm{Y}_{\mathrm{ACP}}=167.87 \mathrm{~m}$ (actual configuration Pietrasanta) which, combined with $\mathrm{Q}_{\mathrm{P}}$, yields a hydraulic power of $\mathrm{P}_{\mathrm{ACP}}=9.81 \times \mathrm{Q}_{\mathrm{P}} \times \mathrm{Y}_{\mathrm{ACP}}=164 \mathrm{~kW}$.



Figure 2. Monthly flow rates Q [1/s] at the "New Aqueduct", from January 2017 to March 2018.

\subsection{Obtainable Power with Pipe Replacements}

The pipes forming the "New Aqueduct" are all in good conditions, except for the last part, from the manhole serving the two derivations for Cesinola to the Pietrasanta reservoir. This portion, sketched in Figure 3, is composed by the succession of steel pipes of diameters DN 450, 300 and 250 with an estimated roughness coefficient of $\varepsilon=0.7 \mathrm{~mm}$.

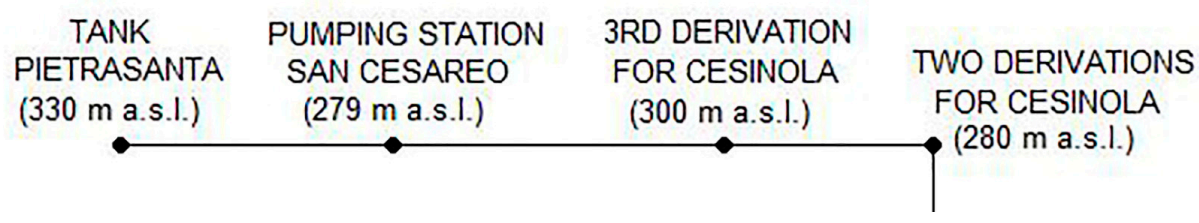

Figure 3. The portion of the "New Aqueduct", object of pipes replacement.

For the new line, an epoxy coated (EC) steel pipe DN 300 with a roughness coefficient $\varepsilon=0.1$ $\mathrm{mm}$ was chosen, according to the economic equation given by Peters \& Timmerhaus [14] for turbulent flow in steel pipes:

$$
\mathrm{D}_{\mathrm{opt}}=0.363 \times \mathrm{Q}^{0.45} \times \mathrm{Q}^{0.13}
$$

where $D_{\text {opt }}$ is the optimal inside diameter in $\mathrm{m}, \mathrm{Q}=\mathrm{Q}_{p}$ is the volumetric flow rate in $\mathrm{m}^{3} / \mathrm{s}$ and $\varrho$ is the water density in $\mathrm{kg} / \mathrm{m}^{3}$.

In this case, applying a roughness coefficient $\varepsilon=0.3 \mathrm{~mm}$ (for used EC pipes), the EPANET model yields a pressure head $16.51 \mathrm{~m}$ higher, that is $\mathrm{YPRP}_{\mathrm{PR}}=184.38 \mathrm{~m}$ (pipe replacement Pietrasanta) which, combined with QP, yields a hydraulic power of PPRP $=181 \mathrm{~kW}$. 


\subsection{The Proposed Solution}

As previously stated, the inflow rate at the Pietrasanta reservoir can be assumed between $50 \mathrm{l} / \mathrm{s}$ and 100 1/s. Corresponding pressure heads Y, computed with EPANET, are summarized in Tables 3 and 4, for the cases described respectively in the Sections 3.1 and 3.2.

Table 3. Pressure heads at the Pietrasanta reservoir for the actual aqueduct (ACP).

\begin{tabular}{cc}
\hline $\mathbf{Q}[\mathbf{l} / \mathbf{s}]$ & $\mathbf{Y}_{\text {ACP }}[\mathrm{m}]$ \\
\hline 50 & 198.21 \\
100 & 167.87 \\
\hline
\end{tabular}

Table 4. Pressure heads at the Pietrasanta reservoir in the case of partial pipe replacement (PRP).

\begin{tabular}{cc}
\hline $\mathbf{Q}[\mathbf{l} / \mathrm{s}]$ & $\mathrm{Y}_{\text {PRP }}[\mathrm{m}]$ \\
\hline 50 & 215.71 \\
100 & 184.38 \\
\hline
\end{tabular}

Assuming a turbine and generator efficiency of the order of $70 \%$ and $85 \%$ respectively, the net power can be expressed in terms of the hydraulic power as:

$$
P_{\text {net }}=0.7 \times 0.85 \times P_{\text {hyd }}=0.6 \times 9.81 \times Q \times Y
$$

Considering the cases corresponding to an inlet flowing discharge $\mathrm{Q}_{\mathrm{p}}=100 \mathrm{l} / \mathrm{s}$ (last rows in Tables 3 and 4) the obtaining net powers are $P_{\text {net, } A C P}=98.81 \mathrm{~kW}$ and $P_{n e t, P R P}=108.53 \mathrm{~kW}$ respectively. Therefore, replacing the pipe as described in Section 3.2 yields a maximum increase of about $10 \mathrm{~kW}$.

IREM, a long established company specialized in design and manufacture of equipment for the control and generation of electric energy, provided indications on the most suitable water turbine to be installed, on the basis of the expected flow rate range and pressure heads.

The proposal fell on a Pelton turbine, shown in Figure 4, particularly intended for medium to high pressure heads. It is provided with a 6-jets distributor [15] that allows compact size and flexible flow regulation in accordance with the expected flow rate, ranging from $50 \mathrm{l} / \mathrm{s}$ to $100 \mathrm{l} / \mathrm{s}$, by means of corresponding six nozzles, ensuring at the same time very good efficiency by changing the flow. The following graph represented in Figure 5 shows an expected developing net power of the order of tens of kilowatts.

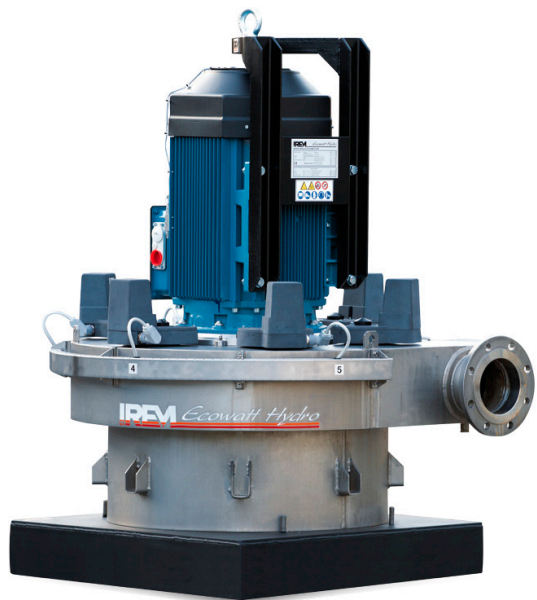

(a)



(b)

Figure 4. The proposed 6-jets distributor Pelton turbine. (a) general view. (b) an example of installation. 


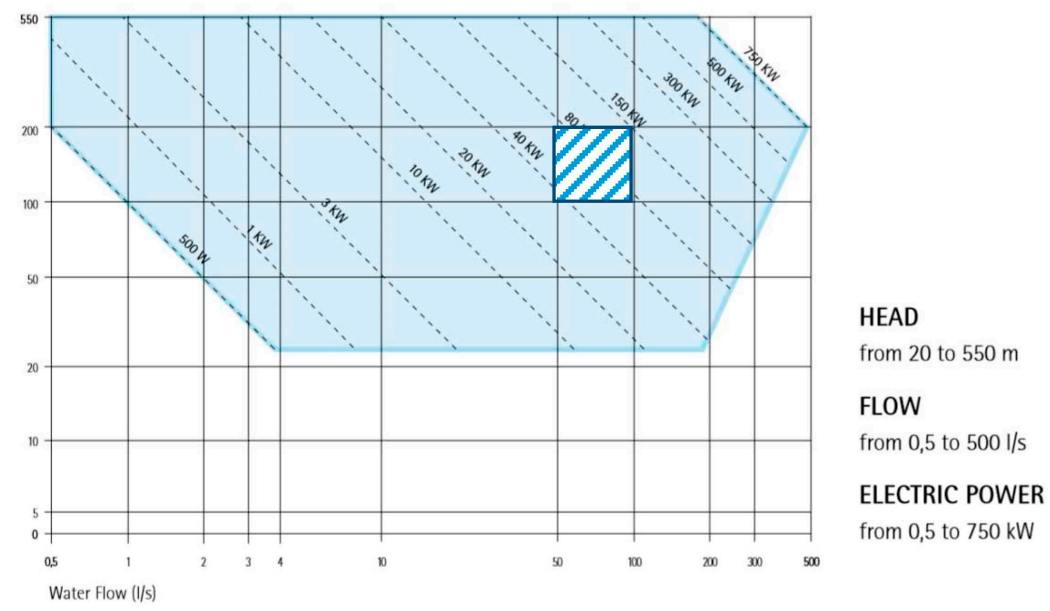

Figure 5. Developing net power for the chosen Pelton turbine. The hatched rectangle represents the expected working area.

\section{Conclusions}

The hydropower potential arising from the installation of a water turbine in the "New Aqueduct", Campania Region, Italy, managed by the 'Ausino S.p.A. Servizi Idrici Integrati' was here assessed, considering the line as it is (ACP solution) and comprehending a partial pipe replacement (PRP solution). Developing net powers were computed, yielding $P_{n e t, A C P}=98.81 \mathrm{~kW}$ and $P_{\text {net,PRP }}=$ $108.53 \mathrm{~kW}$ respectively. On the basis of the working conditions, a multi-jet Pelton turbine was proposed as solution.

Author Contributions: The tasks of conceiving the RES solution; analyzing data, drawing conclusions and writing the paper were uniformly shared among the authors.

Acknowledgments: The authors express their gratitude to the Italian company IREM for the support provided on the possible selection of water turbines to be installed on the New Aqueduct.

Conflicts of Interest: The authors declare no conflict of interest.

\section{References}

1. Viccione, G.; Immediata, N.; Cimmino, M.; Evangelista, S. A laboratory investigation of a domestic hydropower model. In Proceedings of the 3rd EWaS International Conference on Insights on the Water-Energy-Food Nexus, Lefkada Island, Greece, 27-30 June 2018.

2. Fiore, P.; Viccione, G.; Ippolito, L. The sustainable refunctionalisation of watermills. Analysis and proposals in a case-study. In Proceedings of the 42nd IAHS World Congress on Housing, Napoli, Italy, 10-13 April 2018; p. 12, ISBN 9788893260404.

3. Karlis, A.D.; Papadopoulos, D.P. A systematic assessment of the technical feasibility and economic viability of small hydroelectric system installations. Renew. Energy 2000, 20, 253-262, doi:10.1016/ S0960-1481(99)00113-5.

4. Soffia, C.; Miotto, F.; Poggi, D.; Claps, P. Hydropower potential from the drinking water systems of the Piemonte region (Italy). In Proceedings of the SEEP 2010 Conference Proceedings, Bari, Italy, 4-7 July 2010.

5. Hamududu, B.H.; Killingtveit Å. Hydropower Production in Future Climate Scenarios; the Case for the Zambezi River. Energies 2016, 9, 502, doi:10.3390/en9070502.

6. Hamududu, B.H.; Killingtveit, Å. Hydropower Production in Future Climate Scenarios: The Case for Kwanza River, Angola. Energies 2016, 9, 363, doi:10.3390/en9050363.

7. Kaldellis J.K.; Vlachou D.S.; Korbakis, G. Techno-economic evaluation of small hydro power plants in Greece: a complete sensitivity analysis. Energy Policy 2005, 33, 1969-1985, doi:10.1016/j.enpol.2004.03.018.

8. Adhikari, R.C.; Vaz, J.; Wood, D. Cavitation Inception in Crossflow Hydro Turbines. Energies 2016, 9, 237, doi:10.3390/en9040237. 
9. Trivedi, C.; Cervantes, M.J.; Gandhi, B.K. Investigation of a High Head Francis Turbine at Runaway Operating Conditions. Energies 2016, 9, 149, doi:10.3390/en9030149.

10. Zolghadr-Asli, B.; Bozorg-Haddad, O.; Chu, X. Effects of the uncertainties of climate change on the performance of hydropower systems. J. Water Clim. Chang. 2018, jwc2018120, doi:10.2166/wcc.2018.120.

11. Majone, B.; Villa, F.; Deidda, R.; Bellin, A. Impact of climate change and water use policies on hydropower potential in the south-eastern Alpine region. Sci. Total Environ. 2015, 543, 965-980, doi:10.1016/ j.scitotenv.2015.05.009.

12. Rossman, L.A. Computer Models/EPANET. In Water Distribution Systems Handbook; Mays, L., Ed.; McGraw-Hill Companies, Inc.: New York, NY, USA, 1999; Chapter 12.

13. Rossman, L.A. EPANET 2 Users Manual; Water Supply and Water Resources Division, National Risk Management Research Laboratory: Cincinnati, OH, USA, 2000.

14. Peters, M.S.; Timmerhaus, K.D.; West, R.E. West. In Plant Design and Economics for Chemical Engineers; McGraw-Hill: New York, NY, USA, 2003; p. 501.

15. Zhang, Z. Multi-jet Pelton Turbines. In Pelton Turbines; Springer International Publishing: Basel, Switzerland, 2016; Chapter 19, pp. 243-246.

(C) 2018 by the authors. Licensee MDPI, Basel, Switzerland. This article is an open access article distributed under the terms and conditions of the Creative Commons Attribution (CC BY) license (http://creativecommons.org/licenses/by/4.0/). 